\title{
IIASRH: An Integrative IoT Approach for Smart Rainwater Harvesting
}

\author{
Praveen Talari, Anirudh M, Sairam M, K Varun Jebakumar
}

\begin{abstract}
Rainwater harvesting is one of the oldest practices used to conserve and optimize water resources. Nowadays, there are a lot of public and private facilities which have well-constructed Rainwater Harvesting systems. Still, they usually can't test the quality of the water preserved and has no mechanism to purify the impure content to make them consumable. Many known techniques are primitive and conventional for today's standards. The existing systems don't provide connective features, water treatment or contingency measures to counteract any problem. Usually, these systems are integrated onto blockchains, AI, and some other domains to innovate a new paradigm. Still, the results are generally considered a gimmick and are not helpful for general usage. This lack of compatibility and features with no effective solution needs to be rectified, and a real-world upgrade is required to construct a connected, safe and effortless system is imminent. Therefore, an integrative domain approach is necessary to facilitate the process to tackle these problems, where one of the major domains in technology, such as IoT, is used. The proposed model addresses the issues native to the conventional method and provides a connective environment with water treatment capabilities to establish an effortless and connected Rainwater Harvesting system through IoT with precise results and scopes that help the said challenges.

Keywords: RWHS, Raspberry Pi 4, Ultrasonic sensors, Water tank level, Water Purity.
\end{abstract}

\section{INTRODUCTION}

W ater resources are depleted at a rapid rate throughout the course of history, which has paved the way for many calamities and complications present in today's society. One of the significant ways where individual conservation of water is done by one of the conventional methods called rainwater harvesting. Water scarcity is one of the major issues that persist throughout the industrial age and intends to rise constantly. NITI Ayog has reported twenty-one cities in India, including the national capital, are expected to run out of groundwater by 2020, which will affect around 100

Manuscript received on November 23, 2021.

Revised Manuscript received on November 29, 2021.

Manuscript published on December 30, 2021.

* Correspondence Author

Praveen Talari*, Department of Computer Science and Engineering SRM Institute of Science and Technology, Ramapuram, Chennai (Tamil Nadu) India.

Anirudh M, Department of Computer Science and Engineering, SRM Institute of Science and Technology, Ramapuram, Chennai (Tamil Nadu) India.

Sairam M, Department of Computer Science and Engineering, SRM Institute of Science and Technology, Ramapuram, Chennai (Tamil Nadu) India.

K Varun Jebakumar, Department of Computer Science and Engineering, SRM Institute of Science and Technology, Ramapuram, Chennai (Tamil Nadu) India.

(C)The Authors. Published by Blue Eyes Intelligence Engineering and Sciences Publication (BEIESP). This is an open access article under the CC BY-NC-ND license (http://creativecommons.org/licenses/by-nc-nd/4.0/) million people. It also stated that approximately $40 \%$ of India's population will not have access to water by 2030 . Due to Urbanization, deforestation, and Industrialization, the conventional ways of the water cycle are degrading, leading to poor groundwater content. Acid Rain also plays a significant factor in the adulteration of water caused due to chemical reactions between compounds like Nitrogen Oxides and Sulphur Dioxide that are discharged into the air by factories and industries. Hence, many practices to conserve water are accommodated, like Rainwater harvesting. It is evident that nitrogen oxide, Sulphur Dioxide and ozone depletion are the main reasons for acid Rain. Human activities such as burnable waste combustion, thermal power plants and automobile usage of fossil fuels help originate the pollutants [1]. Since these practices cannot be highly controlled under supervision, the necessary measures to handle the situation is imminent.

From the projected representation [2]

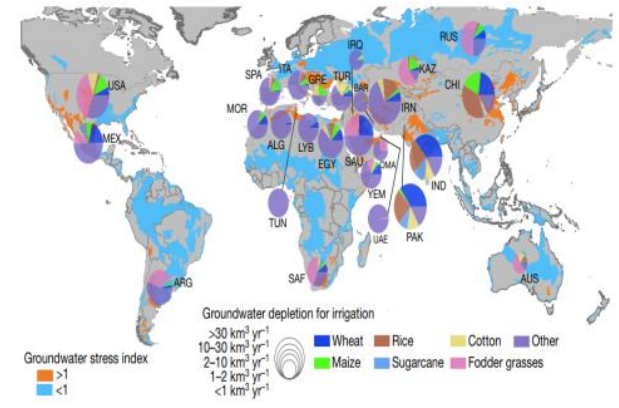

Fig 1. groundwater depletion worldwide in 2010.

Due to water withdrawals for irrigation, there have been alarming rates of groundwater depletion worldwide that are both located and quantified. Exhaustion of such natural resources has led to a massive decline in food production all over the world, in which India has a GWD (Ground Water Depletion) of national output by $4.0 \%$ [2]. Earlier on, some conventional methods were accompanied to tackle these issues, which include some techniques that are primitive.

In situ RWH: In this method, the rainfall is stored in the soil when it falls onto the surface. This method aims to improve the water content holding capacity, soil fertility and protect it against soil erosion.

External RWH: Here, the runoff Rainwater is collected on a surface and stored separately, which are used for various purposes other than consumption.

Domestic RWH (DRWH): This is one of the most widely used methods in Urban and Residential areas, where the water is collected on the rooftops of each individual house or building complex, including street and courtyard runoffs.

Published By:

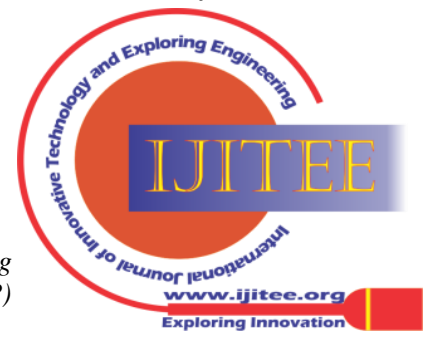


These are the major conventional rainwater harvesting techniques that were and still are used in many parts of the world [3]. Although these methods were once high yielding and helpful based on today's world, the same cannot be still practiced. Since the many challenges have outgrown the simple solutions, it is time to upgrade and update the entire process for the modern-day. From lack of treatment of the collected acid Rain to the unreliability of specific automated RWH systems, every single one of these challenges and complications in the conservation of rainwater is to be analyzed and reviewed based on modern standards.

\section{RELATED WORKS}

Ranjan et al., [1] have proposed a Smart rainwater harvesting system that is completely automated and is integrated into IoT. It uses three different kinds of sensors like ultrasonic, rainfall, $\mathrm{pH}$ to find their appropriate attributes and then redirect the flow of water using servo motor onto two different tanks.

The complete interaction and data transmission is sent to an IoT microcontroller called NodeMCU. V. R. Vanthof et al., [2] have proceeded with a unique development using recorded data from sentinel1-1A(S-1A) sensor with a DEM integration and TerraSAR-X monitors as the water volume changes within the used tank structures. It uses remote sensing to monitor water reservoirs and RWH tanks to find its evaporation rate during seasonal changes. Which suggests the usage of insulated rainwater tanks and their ideal water evaporation rate. $\mathrm{B}$.

Lasya et al., [3] have used another method that would use a model where a prototype model is designed for the RWH system, with the integration of a filtration method and an information transceiver through IoT. The IoT device here is the Uno Arduino which is used as the microcontroller that is used to automate the process. It uses several layers of filtration process to completely extract the pure water from the incoming rainwater without any manual work required. Sharma et al., [4] have constructed their model using a similar NodeMCU Arduino board to make the process automated. It uses two tanks; one is an underground tank and the other is a main tank.

The runoff rainwater is collected, filtered, and are redirected to these two tanks in a hierarchical manner. The entire process is powered by solar panels. Mary Semaan et al., [5] brings us a method where Statutory Liquidity Ratio (SLR) is used for the optimal sizing of RWHS to get an ideal RWHS Tank capacity based on the Rainfall data collected. This model uses statistical analysis of the ideal tank capacity for an RWH system based on historical rainfall data.

This can be efficient and cost friendly to proceed with the process. Maulekhi et al., [6] aims to upgrade the conventional water harvesting technique by automating the process of water usage from water harvesting tanks.

This system is mainly focused on storing the data related to the usage of water by various users. It uses blockchain technology to store this information and keep track of the utilization of different sensors connected such as Relay Module, Water flow sensors, Node MCU and ultrasonic sensors to the Internet of Things (IOT). All the features makes the system transparent and tamperproof
Behzadian et al., [7] The smart RWH scheme proposed here are capable of controlling the water level in the tank to ensure that the spare storage capacity is always maintained.

This study explores the various advantages of using smart RWH schemes for improving the efficiency of integrated Urban Water Systems (UWS).

Its tank can abate local floods during rainfall scenarios and can supply the harvested rainwater to non-potable residentials for consumption. The performance of the UWS can be assessed using the WaterMet2 model with smart RWH schemes.

M. J. Mudumbe et al., [8] introduce a method that uses a smart water meter that will be monitored by the user and will help them reduce their water usage. It can also alert them when they over-use water.

This system is based on the IEEE 802.15.4 wireless sensor network (WSN) and is used to monitor and control water quality. ContikiOS LibCoAP is an open-source application that was used to create the system through visualisation and monitoring achieved using web-based systems and Pandora FMS. C. K.

Kumar Reddy et al., [9] propose a framework that introduces an idea to modernize water harvesting using a well-known setup that incorporates a wide area in which a water sensor is controlled with the help of an Arduino that operates as a guide to the system. A servo engine is integrated with the water sensor which is fuelled through the Arduino.

The water sensor decides the operation of the signals that are sent to the Arduino, servo engine is launched by the Arduino and the end goal is to make water accumulation open, this also triggers an electronic mail to indicate its status to the user. Martin Oberascher et al., [10] Smart rain barrels are made to be used for temporary storage and control of storm water. They can also be used for harvesting rainwater. The concept of a smart rain barrel combines LID and ICT in a single system.

Fletcher et al., [11] use a Real Time Control technology in Rain Water Harvesting system to improve performance for water supply, environmental flow protection and flood protection. It uses four techniques that include Flood protection, which is used to minimize the tank overflows through 24 hour uniform release of any overflows, Supply maximization is a process that involves increasing the amount of tank water that's available for supply and preserving the flow of water.

It's done to minimize the effects of storm release and maximize efficiency.Dalin et al., [12] establish a study on food trade route and their impacts on ground water depletion and water holding potential of various regions.

Helmreich et al., [13] has elaborated the various techniques in rainwater harvesting and explains about the desalination method. Bhargava et al., [14] describes about acid rain and its ecological consequences that were widely accepted in many countries.

Published By:

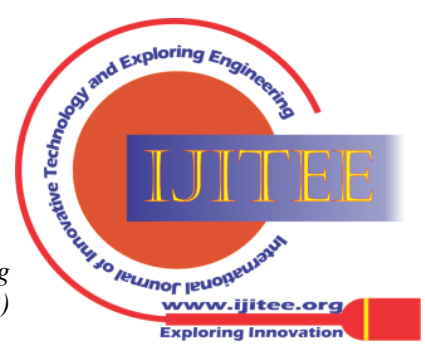




\section{PROPOSED SYSTEM}

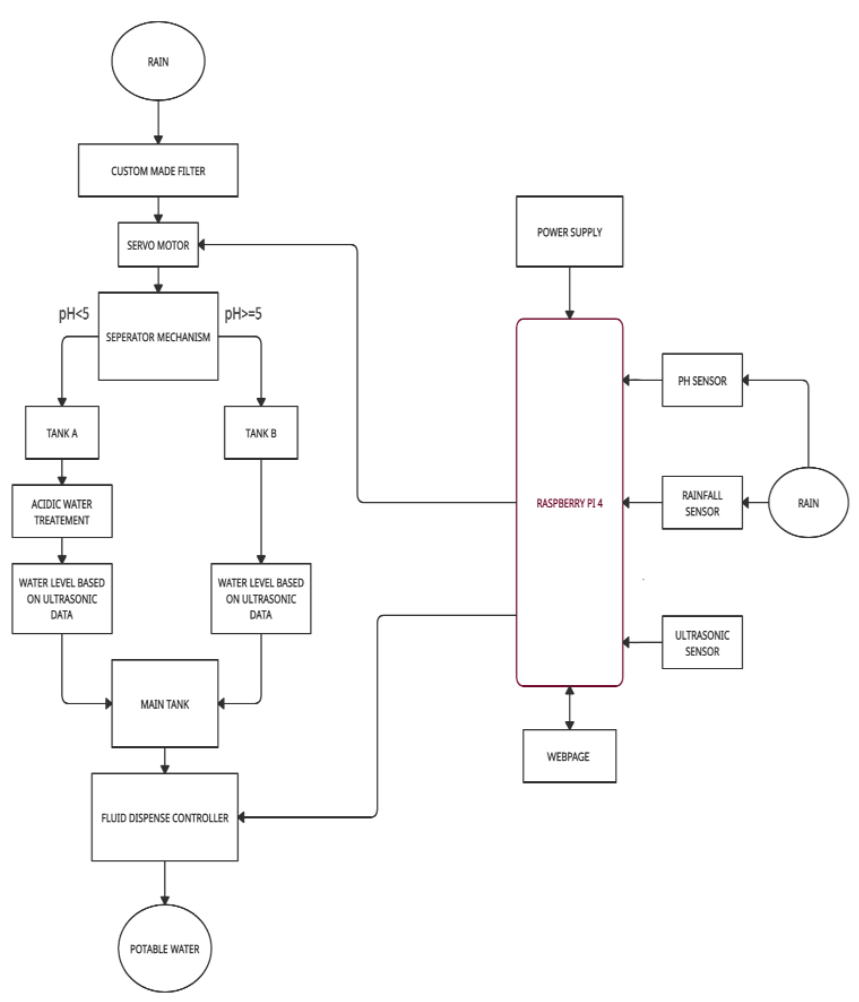

Fig 2. Proposed RWH system architecture

Fig. 2. Depicts the system architecture proposes three major microelectronics such as an IOT controller, actuator, and sensors. Where they are integrated together using a webpage interaction page to complete the entire process. Starting with the Rainfall sensor, where the sensor starts the process once it detects rainfall. Data transmission from the said sensor is effortless which helps the controller identify when to start or stop the entire process and analyze its current water conservation cycle. Next the $\mathrm{pH}$ sensor helps in finding the $\mathrm{pH}$ of the incoming rainfall. Once the $\mathrm{pH}$ is determined, the data is sent to the controller in this case, The Raspberry pi 4 to calculate its current Acidity. If the data received denotes that it lies between 1-5, It is considered as Acidic and if the range lies above 5 it is then concluded as Neutral. Based on the $\mathrm{pH}$ value, The controller gives instruction to redirect it to either the A or the B separate tanks of 5L each, where the process passes through a filtration test. The two tanks are primarily attached with two ultrasonic sensors each which records and transmits the liquid level in each of the tanks. Tank A contains the Acidic water that is to be treated and Tank B contains the normal or neutral water. Tank A is treated with Sodium Hydroxide and Soda Ash which are stored in a cartridge attached inside the tank with an easily replaceable side draw. It takes about 5 mins to treat the acidic water, even though it's a fast process. Finally, the treated and normal rainwater are collected in the main tank of 50 litres capacity which is also attached by an ultrasonic sensor. This tank acts as the final rendezvous, in which the output is attached to an automated water dispensary kit. This kit helps control the water level of the main tank and can be manipulated for each season throughout the years. All these devices are insulated in such a way that there is less to zero water damage. The entire process is set to be timed at approximately 30 minutes to complete for an average case, 15 minutes for the best case and 60 minutes based on the worst case. Meanwhile, the webpage we've created will take advantage of the controller to process, calculate, and control the entire process based on the user preference.

Components used:

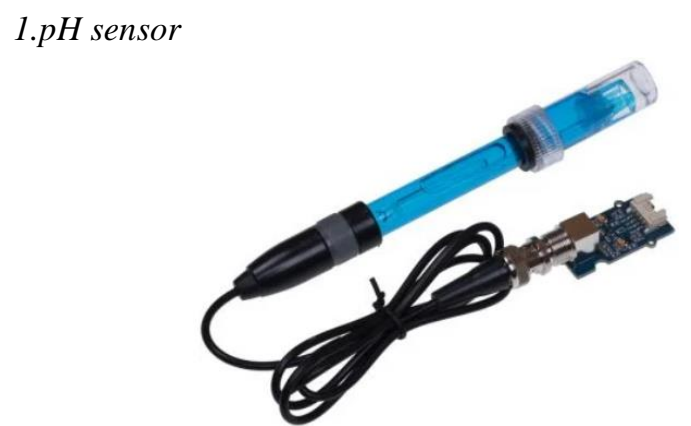

This is a sensor that measures the $\mathrm{pH}$ of the surrounding environment. It uses a common glass electrode to measure the hydrogen ion concentration in an electrolyte solution. In chemistry, $\mathrm{pH}$ is a measure of acidity or basicity. A pH level greater than 7 indicates an alkaline substance, while a $\mathrm{pH}$ level less than 7 signifies an acidic one. The $\mathrm{pH}$ scale ranges from 0 to 14 with 0 being perfectly acidic and 14 being perfectly basic. This sensor is connected to the raspberry pi board with $5 \mathrm{~V}$ power supply, one GPIO pin and one ground pin.

\section{Ultrasonic sensor}

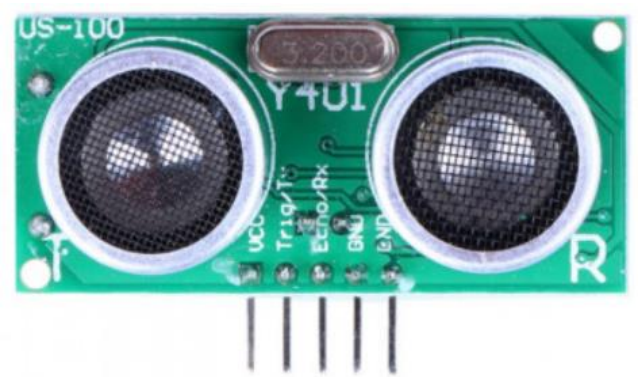

Ultrasonic sensors receive ultrasonic waves, which are high frequency sounds just above the range of human ability to hear. The ultrasound sensor detects these sounds and converts them into an electrical signal that is proportional to the level of sound in the received area. Some applications of this technology are for security purposes with regard to monitoring or measuring distances or sizes of objects, as well as for animal monitoring. In this model, it used to measure the water level in all the tanks used. It uses a Trig and Echo pin connection to transmit data, so they are connected to two GPIO pins and requires a $5 \mathrm{~V}$ power supply pin.

\section{Servo Motor}

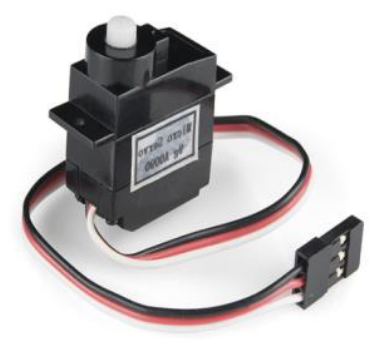

Servo motors are the primary type of electric motor in use today. While an average DC motor uses a constant voltage supply, a servo operates on a pulse-width modulation (PWM) signal input.

Published By:

Blue Eyes Intelligence Engineering and Sciences Publication (BEIESP)

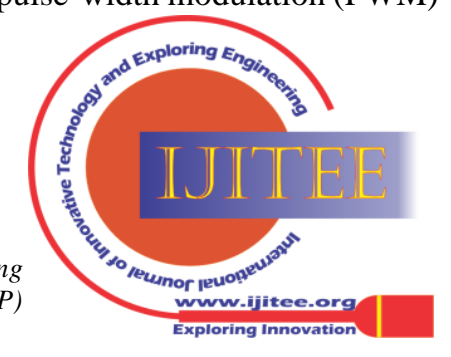


PWM creates an output that is constantly changing between 0 and 100 percent, which makes the servo rotate at varying speeds without stopping. A servo can also rotate 180 degrees to another position upon receiving another PWM signal, as opposed to the standard DC motor which has only one rotation direction. Thus, it makes it easier to direct the water flow to either one of the two tanks. Its pins are connected with series of $5 \mathrm{~V}$, GPIO and ground terminals of the raspberry pi.

\section{Rainfall Sensor}

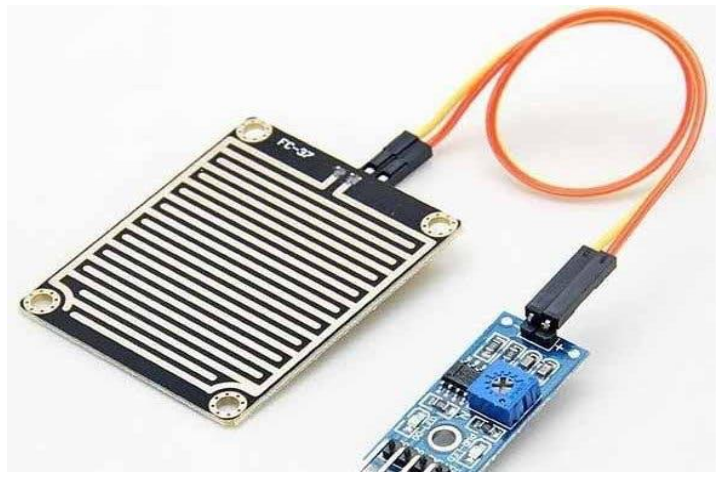

Rainfall sensor helps us to monitor rain and storm conditions. Rainfall sensors are specifically designed to detect the presence of rain and measure its amount over time. Some models also collect wind speed and pressure measurements which may increase the accuracy of rainfall estimates but here it is completely used to record or to detect the time of rainfall and to alert the RWH system to further begin the process. It is connected to the $5 \mathrm{~V}$ supply, GPIO pin and grounded within the raspberry pi.

\section{Automatic Water Dispenser}

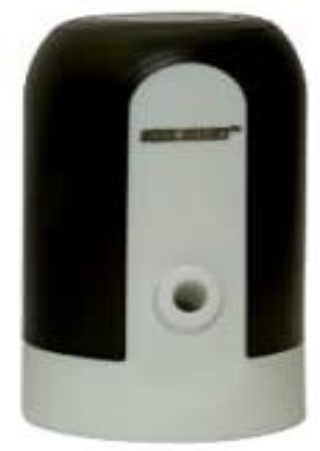

Automatic water dispensers are the forefront of the model, it includes the main feature of pumping the water collected from the main tank in required or requested amount by the system or the user. It is connected to a $110 \mathrm{~V}$ power supply and also to the GPIO board of the Raspberry Pi 4.

\section{Raspberry pi 4}

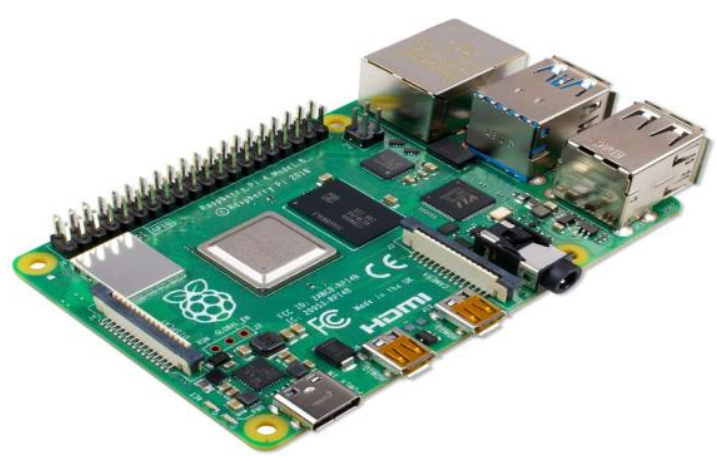

Retrieval Number: 100.1/ijitee.A95851111121
The Raspberry pi 4 is a mini-computer that is powerful and versatile for its form factor. With support for an impressive range of operating systems and applications. It's a complete credit-card sized PC that can be used for anything from digital signage to home automation. Programming languages such as Python and Scratch are used to program the Raspberry pi 4 and it also includes a whole host of features not possible before on previous models. In the proposed model, the raspberry pi 4 is positioned as the main microcontroller that automates the entire process based on user preference. The proposed model also informs that the entire process is facilitated using the website https://create.arduino.cc/iot/dashboards/7ed93773-0e84-4ee 4-956b-869f4ea2a98b and were integrated to PhpMyAdmin as database with MySQL. The process was hosted on https://create.arduino.cc/iot using PhpMyAdmin in accordance with postman application. The Webpage displays all the process that are being executed and not. Main tank capacity, Acid tank capacity, Normal tank capacity, $\mathrm{pH}$ of water, Rainfall status and Water Dispensing status are all displayed on the UI.

\section{IMPLEMENTATION AND RESULT ANALYSIS}

The following experiment was conducted using Raspberry $\mathrm{Pi}$ 4, Three Ultrasonic sensors, one $\mathrm{pH}$ sensor, one Rainfall sensor, one Automatic liquid dispenser and a customized water filter layer for the hardware front and for software, MyPhpAdmin is used to store the database using MySQL and was connected through Arduino Cloud IoT.

The tables 1,2 and 3 depicts the database model used to notify and to record the experiments performed. The database model is of three types from Quantity, Quality and Dispenser modules. MyPhpAdmin is incorporated to conduct the experiment for the database front.

A pair of 2 Litre small tanks and a 5 Litre tanks were used to conduct the experiment with the above apparatus. A customized water filter was used to separate impurities and dust particles at the preliminary stages. For Acidic water, a solution of water mixed and with lemon juice were used. The precise results were yielded from the experiment and took over 10 mins for the conversion of acid water to normal water using Sodium hydroxide and Soda Ash. The servo motor performed well using a lightweight sheet of plastic cover to separate the collected water. All the above processes were monitored, recorded and manipulated using the webpage that was proposed.

Table 1. Database model of Quality parameter in proposed RWHS

\begin{tabular}{|c|c|c|}
\hline Current state(id) & $\mathbf{p H}$ of water(pH) & Rainfall(rnf) \\
\hline 1 & 5 & ON \\
\hline 2 & 7 & ON \\
\hline 3 & 4 & ON \\
\hline 4 & 6 & ON \\
\hline 5 & 5 & OFF \\
\hline
\end{tabular}

Published By:

Blue Eyes Intelligence Engineering and Sciences Publication (BEIESP) 4 (C) Copyright: All rights reserved.

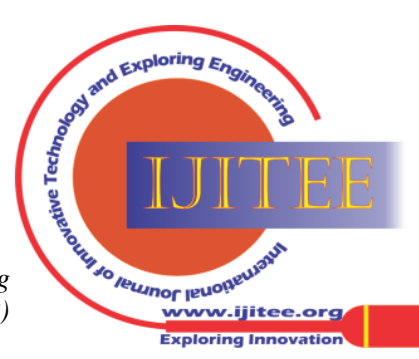


Table 2. Database model of Quantity parameter in proposed RWHS

\begin{tabular}{|c|c|c|c|}
\hline $\begin{array}{l}\text { Current } \\
\text { state(id) }\end{array}$ & $\begin{array}{l}\text { Water level in } \\
\text { Main tank } \\
\text { (Litres) }\end{array}$ & $\begin{array}{l}\text { Water level in } \\
\text { Main tank } \\
\text { (Litres) }\end{array}$ & $\begin{array}{l}\text { Water level in } \\
\text { Main tank } \\
\text { (Litres) }\end{array}$ \\
\hline 1 & 0 & 0 & 2 \\
\hline 2 & 2 & 0 & 1 \\
\hline 3 & 3 & 2 & 0 \\
\hline 4 & 5 & 0 & 2 \\
\hline 5 & 2 & 0 & 0 \\
\hline
\end{tabular}

Table 3. Database model of Dispenser parameter in proposed RWHS

\begin{tabular}{|c|c|c|}
\hline Current state(id) & Device status & Limit to be dispensed \\
\hline 1 & OFF & 0 \\
\hline 2 & OFF & 0 \\
\hline 3 & OFF & 0 \\
\hline 4 & OFF & 0 \\
\hline 5 & ON & 5 \\
\hline
\end{tabular}

\section{CONCLUSION}

A Smart Rainwater Harvesting system is developed that uses a water treatment approach. The proposed system focuses on treating the unusable water that is collected and treated using sodium hydroxide and soda ash. The entire process is also connected using webpages that helps the user for an effortless experience. These enhancements make our model much yielding and upgraded compared to the traditional approach. The resultant water collected can be used in domestic, Industrial, economic and also for potability.

\section{REFERENCES}

1. Ranjan, V., Reddy, M. V., Irshad, M., \& Joshi, N. (2020, March). The Internet of Things (IOT) Based Smart Rain Water Harvesting System. In 2020 6th International Conference on Signal Processing and Communication (ICSC) (pp. 302-305). IEEE.

2. V. R. Vanthof and R. E. J. Kelly, "Rainwater Harvesting in India: Using Radar Remote Sensing Observations to Monitor Water Storage," IGARSS 2018 - 2018 IEEE International Geoscience and Remote Sensing Symposium, 2018, pp. 8404-8407, doi 10.1109/IGARSS.2018.8517750.

3. B. Lasya, Y. Bhavana, B. Deekshitha and B. K. Priya, "An Innovative and Effective Electronic Based Automatic Rainwater Harvesting System," 2020 Third International Conference on Smart Systems and Inventive Technology (ICSSIT), 2020, pp. 114-121, doi: 10.1109/ICSSIT48917.2020.9214118.

4. Sharma, V., \& Nayanam, K. (2020). Arduino based Smart Water Management. International Journal of Engineering Research \& Technology (IJERT), 9, 652-656.

5. Mary Semaan, Susan D. Day, Michael Garvin, Naren Ramakrishnan, Annie Pearce, "Optimal sizing of rainwater harvesting systems for domestic water usages: A systematic literature review", Resources, Conservation \& Recycling: X, Volume 6, 2020, 100033, ISSN 2590-289X, https://doi.org/10.1016/j.rcrx.2020.100033.

6. A. Maulekhi, K. A. Patani, V. Sangani and M. V. Pawar, "The Blockchain-based Smart Water Harvesting System," 2020 International Conference on Smart Electronics and Communication (ICOSEC), 2020, pp. 771-776, doi: 10.1109/ICOSEC49089.2020.9215383.

7. Behzadian, Kourosh \& Kapelan, Zoran \& Mousavi, Jamshid \& Alani, Amir. (2018). Can smart rainwater harvesting schemes result in the improved performance of integrated urban water systems?
Environmental Science and Pollution Research. 25. 10.1007/s11356-017-0546-5.

8. M. J. Mudumbe and A. M. Abu-Mahfouz, "Smart water meter system for user-centric consumption measurement," 2015 IEEE 13th International Conference on Industrial Informatics (INDIN), 2015 pp. 993-998, doi: 10.1109/INDIN.2015.7281870.

9. C. K. Kumar Reddy, P. R. Anisha, R. Shastry, B. V. Ramana Murthy and V. Padmakar, "Automated Rainwater Harvesting System," 2019 International Conference on Communication and Electronics Systems (ICCES), 2019, pp. 479-483, doi: 10.1109/ICCES45898.2019.9002275.

10. Martin Oberascher, Jonatan Zischg; Ulrich Kastlunger, Martin Schöpf,

Carolina Kinzel, Christoph Zingerle, Wolfgang Rauch, and Robert Sitzenfrei," Advanced Rainwater Harvesting through Smart Rain Barrels”, World Environmental and Water Resources Congress 2019: Watershed Management, Irrigation and Drainage, and Water Resources Planning and Management . 2019.

11. Xu, W. D., Fletcher, T. D., Burns, M. J., \& Cherqui, F. (2020). Real time control of rainwater harvesting systems: The benefits of increasing rainfall forecast window. Water Resources Research, 56, e2020WR027856. https://doi.org/10.1029/2020WR027856

12. Dalin, C., Wada, Y., Kastner, T., \& Puma, M. J. (2017). Groundwater depletion embedded in international food trade. Nature, 543(7647), 700-704.

13. Helmreich, B., \& Horn, H. (2009). Opportunities in rainwater harvesting. Desalination, 248(1-3), 118-124.

14. Bhargava, S., \& Bhargava, S. (2013). Ecological consequences of the acid rain. IOSR J. Appl. Chem, 5, 19-24.

\section{AUTHORS PROFILE}

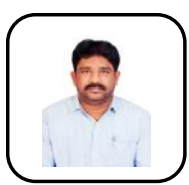

Praveen Talari, Department of Computer Science and Engineering, SRM Institute of Science and Technology, Ramapuram, Chennai.

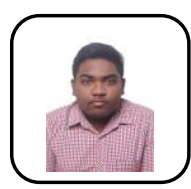

Anirudh M, Department of Computer Science and Engineering, SRM Institute of Science and Technology, Ramapuram, Chennai

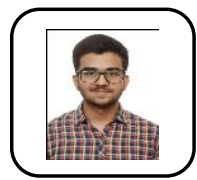

Sairam M, Department of Computer Science and Engineering, SRM Institute of Science and Technology, Ramapuram, Chennai

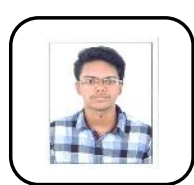

K Varun Jebakumar, Department of Computer Science and Engineering, SRM Institute of Science and Technology, Ramapuram, Chennai
Published By:

Blue Eyes Intelligence Engineering and Sciences Publication (BEIESP) 5 (C) Copyright: All rights reserved.

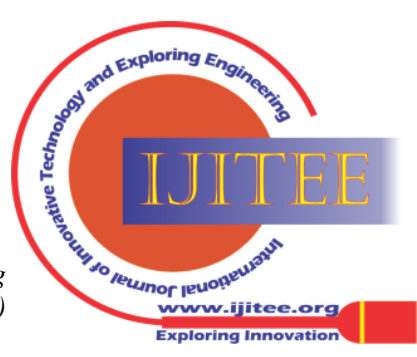

